\title{
Construcció de ludions
}

\author{
Lluís Nadal i Balandras $\bowtie$ \\ Centre de Documentació $i$ Experimentació de Ciències (CESIRE - CDEC)
}

Es presenten diferents formes senzilles de construir un ludió o diable de Descartes amb materials a l'abast.

Paraules clau: ludió, flotabilitat, principi d'Arquimedes, principi de Pascal

El ludió o diable de Descartes consisteix en un recipient obert per sota, contenint una cambra d'aire i ficat en un recipient tancat ple d'aigua. Quan augmenta la pressió sobre l'aigua del recipient el ludió s'enfonsa i quan es torna a disminuir la pressió, sura.

El ludió no només és una joguina sinó que permet evidenciar el principi de Pascal (una pressió feta en un punt d'un fluid es transmet a tots els altres punts) i alguns aspectes sobre l'empenyiment d'Arquimedes i la compressibilitat dels fluids.

\section{DIFERENTS TIPUS DE LUDIONS}

\section{Ludió de Ilumí}

El ludió més simple és un llumí de paper parafinat ficat en una ampolla de plàstic flexible transparent (una ampolla de refresc d'un o dos litres) plena d'aigua i tapada (fig. 1).

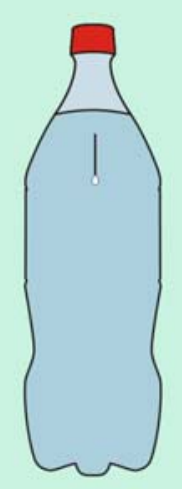

Figura 1. Ludió de llumí de paper parafinat.
Té l'inconvenient de no permetre veure quin és el fonament del seu funcionament $\mathrm{i}$ de vegades s'ha de fer molta força perquè s'enfonsi.

\section{Ludió amb comptagotes}

També es pot utilitzar un comptagotes parcialment ple d'aigua amb un filferro com a llast, de manera que tot just suri (fig. 2). Es pot veure que al fer pressió, l'aire, que és compressible, disminueix de volum i el seu lloc és ocupat per més aigua, el volum de fluid desplaçat disminueix, l'empenyiment d'Arquímedes es fa més petit que el pes i el ludió s'enfonsa.

Quan es deixa de fer pressió, l'aire recupera el volum inicial fent sortir el volum corresponent d'aigua de manera que l'empenyiment es fa superior al pes i el ludió sura.

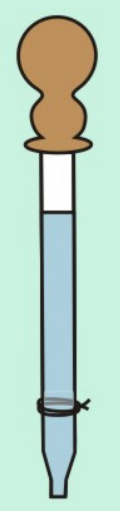

Figura 2. Un comptagotes amb un filferro com a llast pot fer de ludió. 
Es pot comprovar el principi de Pascal que afirma que la pressió es transmet a qualsevol punt del fluid: el resultat és el mateix, independentment del punt de l'ampolla on es faci la pressió.

El filferro a la llarga s'oxidarà, fent que el ludió s'enfonsi. Es pot evitar utilitzant un filferro inoxidable.

\section{Ludió amb tap de bolígraf}

Es pot fer un ludió més durable amb un caputxó de plàstic d'un bolígraf (o un tub de plàstic tancat per dalt), encolat amb Araldit a un tub de vidre prou llarg perquè s'enfonsi (figs. 3 i 4).

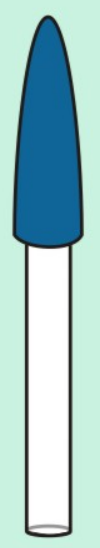

Figura 3. Ludió fet amb un tap de bolígraf enganxat a un tub de vidre.

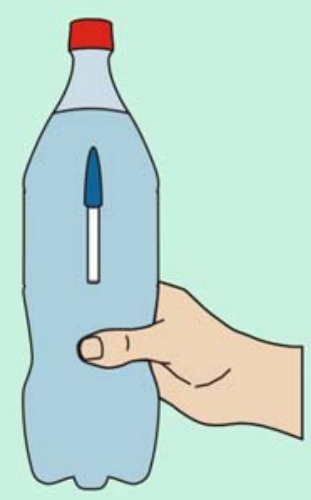

Figura 4. Prement l'ampolla el ludió s'enfonsa.

Després es van tallant petits trossos del tub de vidre fins que el ludió tot just suri.
També es pot bufar a la flama una petita ampoIla a l'extrem d'un tub de vidre i tallar-ne petits trossos de tub fins que suri (fig. 5).

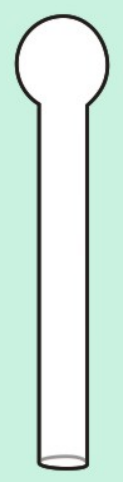

Figura 5. Ludió fet amb tub de vidre bufat.

Aquest ludió funcionarà indefinidament si s'utilitza agua destil.lada (per evitar que s'alliberin gasos) i no es gira l'ampolla de cap per avall (al fer-ho, el ludió pot quedar ple d'aigua i enfonsar-se).

\section{Ludió hidrostàtic}

S'afegeix un tub de plàstic flexible d'1,5 m al tap de l'ampolla i s'omple d'aigua. Quan s'aixeca el tub (fig. 6), augmenta l'altura d'aigua sobre l'ampolla; això comporta un augment de la pressió dins de l'ampolla i el ludió s'enfonsa.

Quan es torna a baixar el tub (fig. 7), el ludió puja. Es pot obtenir el mateix resultat tapant el tub amb el dit i prement l'ampolla.

El ludió no puja amb la mateixa altura de tub que quan s'enfonsa degut a que a la part inferior de l'ampolla hi actua una pressió hidrostàtica més gran que a la part superior.

Un altre aspecte interessant és que és difícil mantenir el ludió en un punt intermedi de l'ampolla. Si el ludió tingués la mateixa densitat que l'aigua podria romandre-hi en qualsevol punt (equilibri indiferent). A la pràctica és pràcticament impossible d'aconseguir que tingui la mateixa densitat i qualsevol diferència, per petita que sigui, farà que pugi o que baixi.

Sí que és possible un equilibri "dinàmic": veient la tendència a pujar o a baixar, es pot fer més o menys pressió i mantenir-lo gairebé en la mateixa posició.

Una altra manera d'aconseguir un cos en equilibri en un punt intermedi d'un fluid és utilitzar un gradient de densitat o dos fluids diferents. 


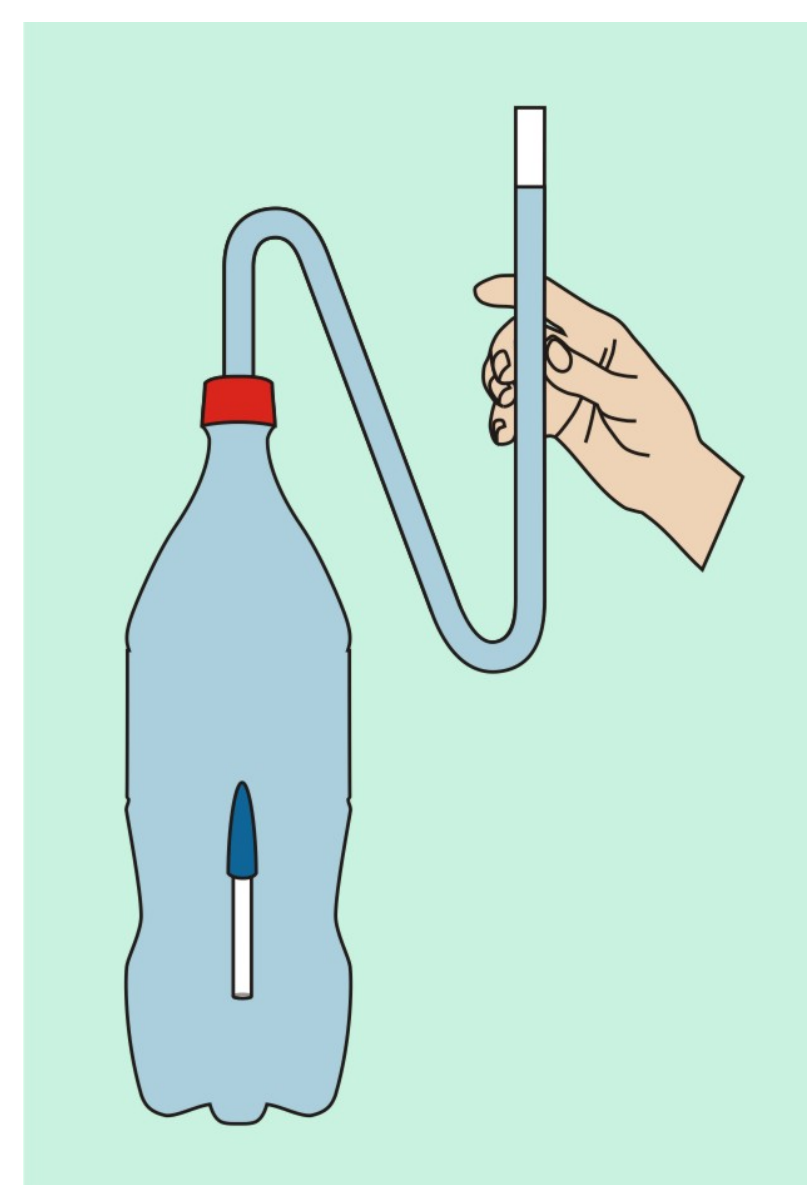

Figura 6. A l'alçar el tub, el ludió s'enfonsa.

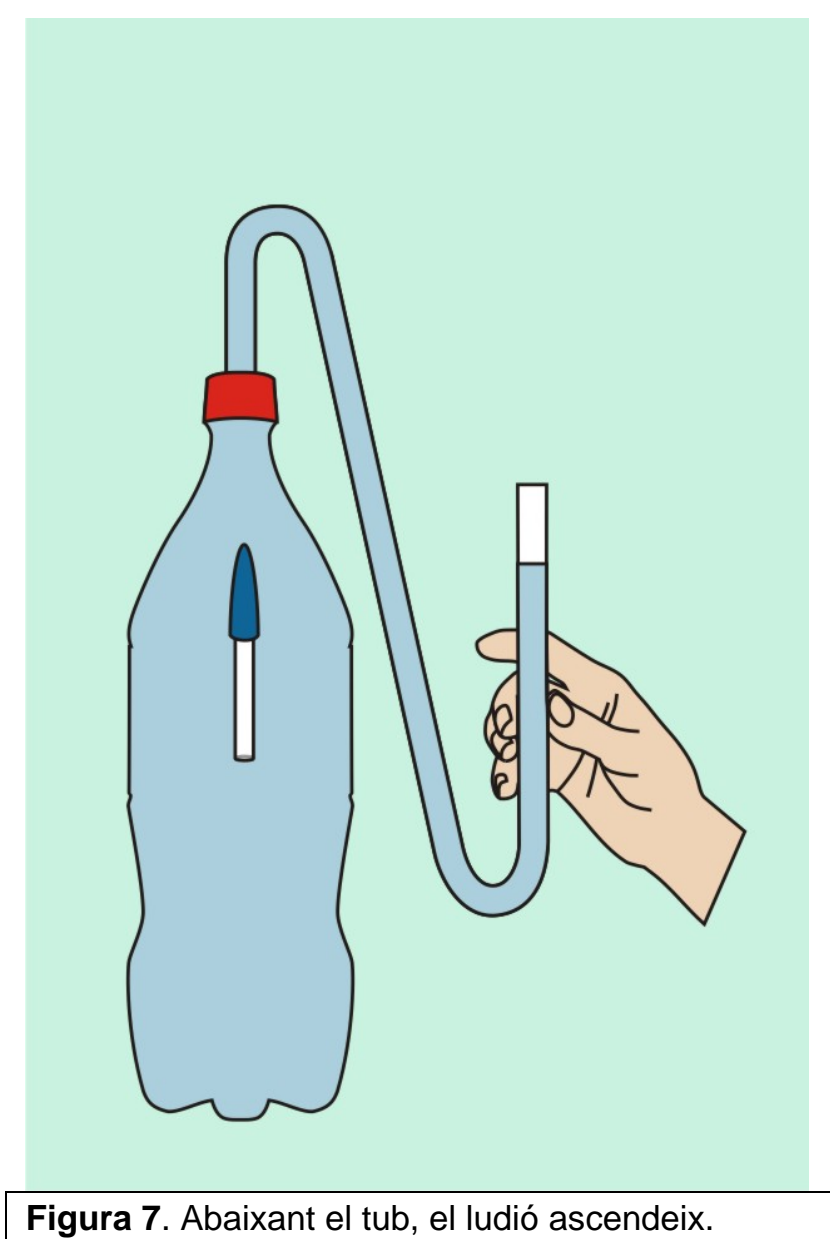

Figura 7. Abaixant el tub, el ludió ascendeix.

Aquests experiments formen part del fons del CESIRE - CDEC (Centre de Documentació i Experimentació de ciències) del Departament d'Ensenyament, Generalitat de Catalunya. 